\title{
PENERAPAN APLIKASI SICERDAS BERBASIS WEB PADA SISWA RAUDHATUL ATHFAL (RA) NURUL HASANAH
}

\author{
Safrizal \\ rizalsy175@gmail.com \\ Lili Tanti \\ lilitanti82@gmail.com \\ Susianto \\ susianto@gmail.com
}

\section{UNIVERSITAS POTENSI UTAMA}

\begin{abstract}
ABSTRAK
Informasi menjadi bagian yang sangat penting dalam dunia pendidikan. Penerapan teknologi dalam pendidikan sangat membantu dalam mencari informasi yang baik bagi peserta didik. Permasalahan yang terjadi saat ini adalah kurangnya penggunaan media teknologi terutama komputer oleh pihak sekolah RA Nurul Hasanah dalam memberikan materi ajar kepada siswa. Sehingga membuat informasi yang diterima oleh siswa kurang update. Selain itu sistem evaluasi dalam bentuk ujian juga masih menggunakan cara-cara manual (paperbased test). Metode kegiatan PKM ini dilakukan dengan membuat sebuah program aplikasi yang berbasis web. Tujuan aplikasi yang dibangun adalah agar pembelajaran lebih menarik serta evaluasi siswa tidak lagi menggunakan cara manual akan tetapi sudah menggunakan aplikasi. Aplikasi tidak hanya sebatas untuk evaluasi melainkan juga dapat memberikan informasi kepada orang tua siswa tentang informasi siswa selama mengikuti pembelajaran di sekolahp. Hasil yang didapat sekolah akan memiliki sebuah aplikasi dan menjadi sesuatu yang baru tentang sebuah media pembelajaran dan evaluasi menggunakan aplikasi SICERDAS yang berbasis WEB.
\end{abstract}

Kata kunci: Aplikasi SiCERDAS, Sistem Informasi, Web.

\section{PENDAHULUAN}

Perkembangannya teknolgogi saat ini memberikan dampak yang besar terutama bagi guru maupun siswa. Para guru juga mengintegrasikan teknologi dalam bidang pengajaran. Teknologi tidak hanya dijadikan sebagai media pembelajaran saja, namun mulai merambah pada proses pembelajaran itu sendir (Arikunto, 2012). Internet dan teknologi digital memiliki peran yang penting dalam dunia pendidikan.
Penggunaan teknologi yang tidak tepat terutama pada proses pendidikan seperti Smartohone, Tablet akan menyebabkan timbulkan efek negatif bagi siswa yang belum bisa mengontrol penggunaan teknologi (Ates, 2013; Rachmaniar et al., 2018; Heni \& Mujahid, 2018; Sobon \& Walewangko, 2019). Sekolah juga memberikan dukungan terkait penerapan teknologi dalam proses pembelajaran, seperti mendukung para guru dalam proses pembelajaran berbasis teknologi dengan 
memberikan pengetahuan melalui media internet yang tentunya berkaitan dengan pembelajaran dan pendidikan.

Pendidikan merupakan faktor sangat penting untuk memastikan kelangsungan hidup suatu bangsa, karena pendidikan dapat meningkatkan dan mengembangkan kualitas sumber daya manusia (Sudarsana, 2016: Muhardi, 2004; Sudarsana, 2018). Seiring dengan perkembangan teknologi informasi dan komunikasi (TIK), banyak sekolah yang sudah menggunakan media teknologi dalam memberikan materi pembelajaran, ujian berbasis online bahan hasil evaluasi siswa juga dapat dilihat melalui online (Rolisca \& Achadiyah, 2014; Afgani \& Purwoko, 2008).

Dalam proses belajar mengajar disekolah mitra dalam hal ini yaitu Raudhatul Atfal Nurul Hasanah belum memanfaatkan teknologi informasi secara maksimal terutama bagi para guru dalam memberikan materi aja. Para guru juga sangat jarang sekali menggunakan media teknologi dalam proses mengajar. Proses belajar mengajar masih menggunakan caracara yang dilakukan pada umumnya. Seperti menggunakan buku ajar dan sebagainya. Pada saat ujian para guru juga masih menggunakan cara-cara yang dilakukan pada umumnya yaitu dengan membuat soal, memperbanyak soal kemudian dibagikan kepada para siswa yang kemudian siswa tersebut mengerjakan soal yang diberikan. Selama ini metode yang digunakan oleh pihak mitra, dalam melakukan monitoring ktivitas kegiatan dan manajemen ujian masih menggunakan soal ujian dalam bentuk kertas (paper based test) yang dibagikan kepada siswa, kemudian hasilnyakan direkapitulasi dan ditulis kedalam buku raport siswa.

Dalam monitoring aktivitas dan kegiatan belajar siswa oleh guru hanya melalui buku penghubung sebagai media komunikasi tertulis antar pihak sekolah dengan orang tua serta buku raport sebagai media informasi terhadap evaluasi hasil akhir siswa dalam kegiatan belajar. Hal ini terkadang menjadi kendala karena komunikasi hanya sebatas tentang hasil belajar tanpa menjelaskan lebih rinci terhadap perkembangan anak selama kegiatan disekolah.

Berdasarkan paparan yang dihadapi leh sekolah mitra yaitu RA Nurul Hasanah, maka dengan ini Tim Hibah PKM Universitas Potensi Utama mengadakan kegiatan pelatihan dan pendampingan dalam mendesain sebuah aplikasi SiCERDAS. Aplikasi ini berbasis web dan dibuat secara online untuk itu diperlukan akses internet. Internet merupakan jaringan komputer yang menghubungkan secara global (Sibero, 2014). Tim Hibah PKM Universitas Potensi Utama sepakat dengan kepala sekolah Raudhatul Atfal Nurul Hasanah menerapkan Aplikasi SICERDAS dalam proses belajar mengajar dalam meningkatkan minat belajar siswa pada RA Nurul Hasanah melaui pendekatan permainan yang dapat menumbuhkan minat belajar siswa dan lebih memotivasi dalam menumbuhkan keingintahuan, pengalaman siswa dalam belajar dan sebagai monitoring evaluasi siswa yang dijadikan sebagai tolak ukur dalam membuat keputusan bagi pihak sekolah dan orang tua.

Aplikasi ini berguna bagi para guru dalam memberikan materi ajar melalui tes uji kemampuan siswa, yaitu dengan memberikan soal-soal dengan tampilan yang lebih menarik sehingga para siswa dalam menjawab soal tidak bosan dan lebih interaktif. Aplikasi ini juga dapat memberikan informasi bagi para orang tua terhadap perkembangan pendidikan anak disekolah. Program kemitraan masyarakat ini bertujuan untuk meningkatkan pengetahuan teknologi informasi bagi para tenaga pendidik dan tenaga kependidikan RA Nurul Hasanah. labuhan. Terkait masalah tersebut program ini menawarkan solusi yang nantinya akan menyelesaikan permasalahan sekolah. Program yang ditawarkan dengan membangun satu aplikasi berbasis web secara online, serta para pendidik dan tenaga kependidikan akan dibekali pengetahuan yang lebih agar 
mereka bisa lebih inovatif (Aka, 2017; Hussin, 2017).

\section{METODOLOGI PELAKSANAAN}

Tim PKM Universitas Potensi Utama mengadakan pelatihan dan memberikan workshop dan kepada para tenaga pendidik dan tenaga kependidikan yang ada di sekolah RA Nurul Hasanah. Berikut diuraikan tahapan kegiatan PKM yang dilaksanakan di sekolah mitra:

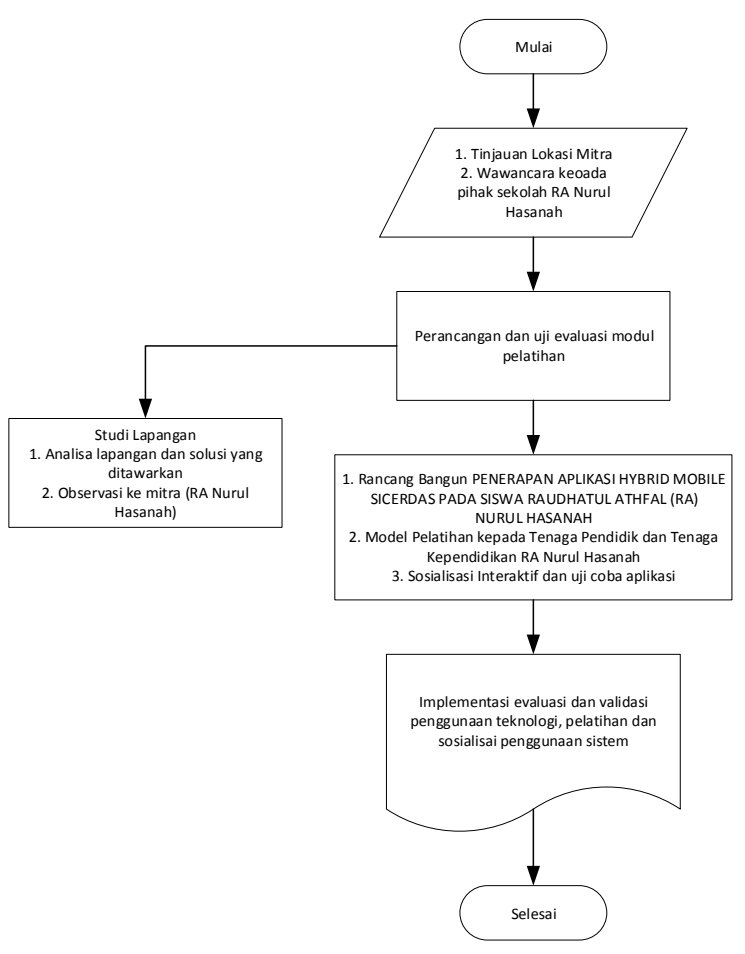

Gambar 1. Tahapan Kegiatan PKM

1. Diawali dengan melakukan kunjungan ke lokasi mitra, letak lokasi mitra yang terletak dijalan Durung Link-18 Pasar-6, Kelurahan Terjun, Kecamatan Medan Marelan, Kota Medan, Provinsi Sumatera Utara.
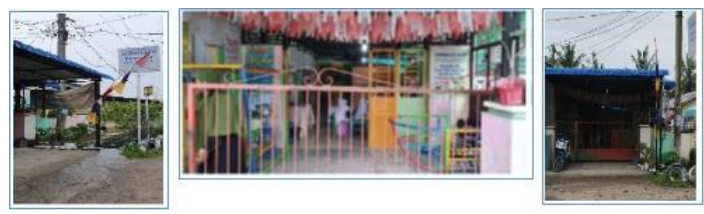

Gambar 2. Lokasi sekolah RA Nurul Hasanah
Pada awal pertemuan Tim Pengusul bertemu langsung dengan ketua Yayasan Nurul Hasanah untuk mendiskusikan awal kegiatan dan teknis pelaksanaan kegiatan guna mengetahui kendala ang di hadapi oleh sekolah mitra dalam hal pembelajaran kepada para siswa. Kegiatan survei, wawancara dan observasi dilakukan secara langsung di sekolah mitra dengan mengikuti protokol kesehatan yang direkomendasikan oleh Kementerian Kesehatan Republik Indonesia dan WHO baik kepada Kepala Sekolah maupun kepada para guru.

2. Berikutnya yaitu tahap yang kedua Tim engusul PKM berdiskusi dan menganalisa hasil untuk mendapatkan solusi dari kendala-kendala yang dihadapi oleh pihak sekolah mitra.

3. Tahapan ketiga tim pengusul menyusun kembali rancangan yang sudah disetujui oleh pihak mitra. dan team mulai merancang aplikasi yang berbasis web.

4. Pada tahapan keempat adalah tahapan pelaksanaan sosialisasi tentang program yang akan direncanakan kepada pihak sekolah dalam hal ini kepada ketua yayasan Nurul Hasanah juga kepada Kepala Sekolah, yaitu engan memberikan informasi tentang program kerja yang akan dilakukan dan juga tentang aplikasi yang akan dibangung serta cara penggunaan aplikasi tersebut.

5. Di tahapan yang kelima, Tim Pengusul PKM mengadakan sosialisasi cara penggunaan aplikasi yang akan dibangun dengan pihak admin dan para guru sebagai pihak yang akan menggunakan aplikasi tersebut.

6. Tahap berikutnya Tim Pelaksana PKM akan mengevaluasi dan memperbaiki aplikasi dari hasil ujicoba yang dilakukan oleh mitra, dan akan menvalidasi keseluruhan aplikasi sistem informasi sekolah.

7. Dalam tahap menvalidasi keseluruhana aplikasi team pelakana mempersiapkan keseluruhan perangkat yang akan 
digunakan dan diberikan ke mitra. Dan team pelaksana PKM akan mensosialisasikan kembali dengan memberikan pelatihan yang ke 2 untuk implementasi langsung aplikasi secara keseluruhan.

8. Setelah kegiatan selesai tim pelaksana PKM akan menyerahkan secara simbolis perangkat pendukung dan aplikasi ke mitra.

\section{HASIL DAN LUARAN}

Adapun kegiatan yang dilakukan oleh Tim PKM Universitas Potensi Utama adalah pengembangan media pembelajaran bagi siswa RA Nurul Hasanah dalam mengoptimalkan penggunaan teknologi. Penggunaan teknologi yang dikembangkan di sekolah mitra adalah penggunaan teknologi berbasis web, di mana aplikasi yang dikembangkan diharapkan dapat membantu pihak sekolah dalam memberikan segala informasi tentang perkembangan belajar siswa kepada orang tua. Diharapkan dengan adanya aplikasi ini pihak sekolah dan orang tua dapat saling bekerja sama dalam perkembangan belajar anak. Pihak sekolah akan saling berkomunikasi kepada orang tua siswa dalam hal kelebihan maupun kekurangan anak dalam belajar.

Tak kalah pentingnya, aplikasi ini juga dapat melakukan evaluasi belajar siswa dengan cara melakukan ujian dengan tampilan yang lebih menarik. Seperti ada suara, video, gambar dan sebagainya. Sehingga diharapkan para siswa akan lebih menikmati ujian mereka dalam bentuk yang berbeda dari sebelumnya yakni hanya berbasis paper base (kertas).

Siswa-siswi akan dapat melihat hasil ujian mereka langsung setelah mereka selesai melaksanakan ujian. Di samping itu, siswa juga bisa melihat soal dan jawaban yang ada sehingga para siswa dapat mengulang materi pelajaran yang berkaitan dengan soal ujian yang gagal mereka jawab, tentunya dengan bantuan guru-guru.
Sesuai dengan jadwal yang telah disusun, maka hasil yang diperoleh dari kegiatan PKM adalah sebagai berikut:

1. Proses yang dilakukan oleh Tim Hibah PKM Universitas Potensi Utama dengan melakukan observasi dan wawancara mengenai langkah-langkah kegiatan PKM yang akan dilakukan di sekolah mitra. Hal ini dilakukan sebagai upaya untuk membicarakan upaya-upaya yang akan dilakukakan dalam menentukan jenis kegiatan dan teknik kegiatan yang akan diterapkan. Fakta yang diperoleh oleh Tim Hibah PKM Universitas Potensi Utama adalah di sekolah mitra melaksanakan sistem ujian dan evaluasi menggunakan cara-cara yang pada umumnya dilakukan oleh sekolahsekolah. Seperti mengadakan ujian berbasis kertas tulis, kemudian sistem evaluasi juga dilakukan melalui buku penghubung antara pihak sekolah dengan orang tua. Berdasarkan hasil observasi dan wawancara diperoleh kesepakatan antar Tim Hibah PKM Universitas Potensi Utama dengan pihak sekolah mitra untuk membuat sebuah program aplikasi yang berbasis web dimana nantinya program aplikasi ini dapat membantu para guru dan siswa dalam membuat sebuah sistem yang lebih menarik dan interaktif antara guru dan siswa.

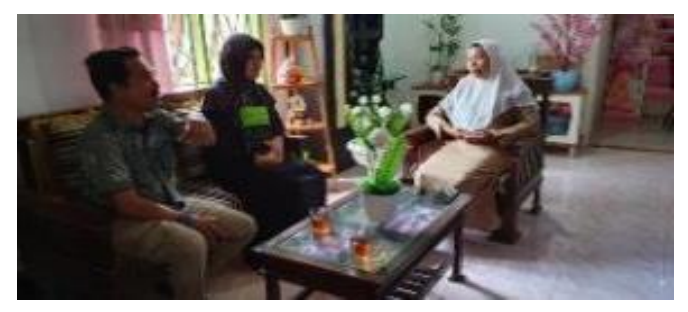

Gambar 3. Sosialisasi Program PKM Kepada Ketua Yayasan RA Nurul Hasanah

2. Kegiatan PKM dimulai dengan pemberian informasi terkait dengan aplikasi yang akan dibuat. Dimulai dari perangkat-perangkat yang akan digunakan sebagai pendukung jalannya aplikasi seperti komputer, internet dan 
sebagainya. Kegiatan diawali dengan pemaparan terkait proses pembuatan aplikasi berbasis web dengan berbagai kemudahan yang nantinya akan diterapkan. Kemudian diskusi tentang sistem yang selama ini dilakukan oleh pihak sekolah dalam hal mengadakan evaluasi dalam bentuk ujian serta hasil yang akan dilaporlan kepada orang tua siswa. Diskusi singkat terkait pengalaman para guru sekolah mitra selama melakukan pengajaran dengan metode yang sudah ada.

3. Kegiatan dilanjutkan dengan pemberian motivasi dan materi terkait tentang penggunaan program, proses pembuatan serta penerapan kepada para anak didik. Karena bentuknya sebuah diskusi maka kegiatan ini berlangsung dengan teknik dua arah dan memberikan kesempatan kepada Ketua Yayasan, Kepala Sekolah, Admin dan para guru sekolah mitra untuk bertanya seputar informasi tentang program aplikasi. Kegiatan ini juga pemberian informasi tentang tata cara pembuatan soal yang lebih menarik baik kepada guru-guru baik soal yang menggunakan suara, gambar, video yang bisa saja dikutip dari media internet.

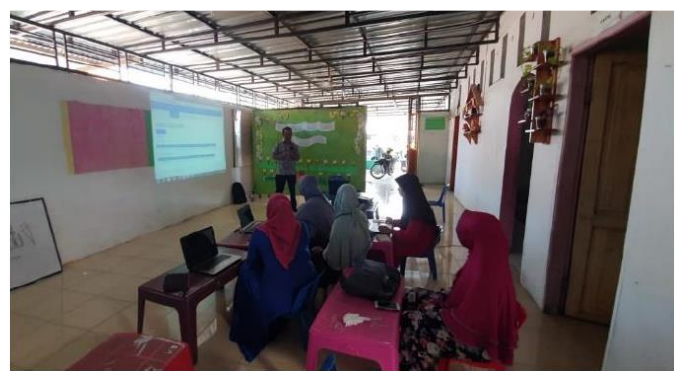

Gambar 4. Sosialisasi Program PKM kepada Jajaran Sekolah RA Nurul Hasanah

4. Sesi berikutnya adalah menyampaikan informasi tentang tata cara penggunaan aplikasi yang berbasis web kepada para admin sekolah dan para guru-guru. Pemberian informasi ini dilakukan mulai dari tahap awal yaitu cara menghidupkan komputer, mengaktifkan aplikasi program, menjalankan program dengan detail sampai kepada hasil yang akan dilihat yang nantinya akan disampaikan kepada siswa.
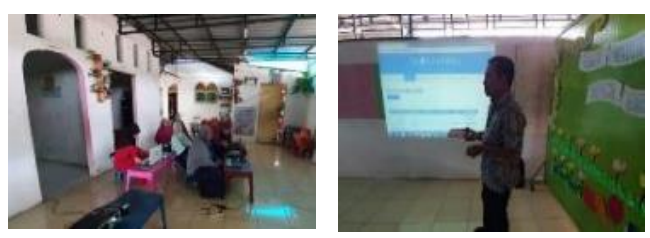

Gambar 5. Sosialisasi penggunaan aplikasi kepada admin sekolah dan guru-guru RA Nurul Hasanah

5. Tahapan selanjutnya adalah melakukan pendampingan penggunaan program kepada siswa-siswi sekolah mitra sebagai pengguna aplikasi. Langkahlangkah pada tahap ini juga dilakukan mulai dari cara menghidupkan aplikasi sampai kepada penggunaan aplikasi program.

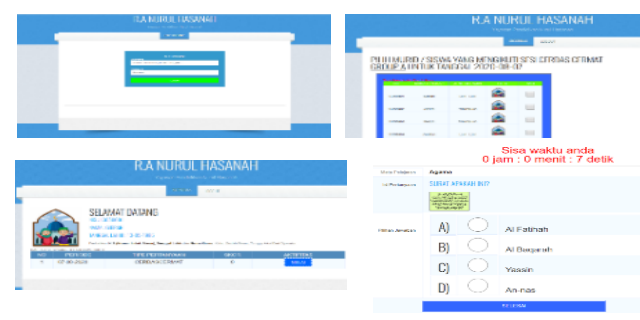

Gambar 6. Tampilan Aplikasi SiCERDAS berbasis web

6. Informasi ini juga disampaikan kepada orang tua siswa, karena orang tua juga ikut berperan aktif dalam penggunaan aplikasi. Dimana orang tua nantinya akan sebagai pendamping para siswa yang akan menggunakan aplikasi dari rumah mengingat masa ini kegiatan sekolah tidak seperti yang sebelumnya. Orang tua juga diajarkan bagaimana menggunakan aplikasi sampai kepada melihat hasil yang diperoleh oleh anak,

7. Tahapan kegiatan terakhir pada kegiatan ini adalah evaluasi terhadap hasil pelatihan dan pendampingan pengembangan penggunaan aplikasi berbasis web Evaluasi dilakukan dengan 
cara membagian angket kuisioner kepada para guru sekolah mitra kegiatan PKM. Kuisioner diberikan kepada guruguru dan juga orang tua. Total responden sebanyak 15 orang.

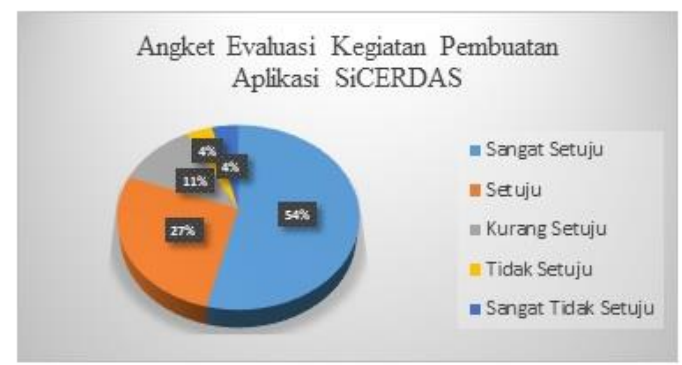

Gambar 6. Hasil Perhitungan Angket Kegiatan PKM

Hasil perhitungan angket kegiatan PKM pelatihan dan pendampingan pengembangan bahan ajar berbasis informasi anti-hoaks dalam meningkatkan keterampilan guru memperoleh rata-rata persentase angket sebesar $80.77 \%$ (sangat setuju dan setuju) dan masuk dalam kategori sangat baik. Hal tersebut sesuai dengan tabel kategori perhitungan angket yang dapat dilihat pada tabel 1 di bawah ini:

Tabel 1. Kategori Perhitungan Angket

\begin{tabular}{|c|c|c|}
\hline No & $\begin{array}{c}\text { Rentang } \\
\text { Persentase Hasil } \\
\text { Angket }\end{array}$ & Katagori \\
\hline 1 & $\begin{array}{c}80 \% \leq P \leq \\
100 \%\end{array}$ & Sangat Baik \\
\hline 2 & $\begin{array}{c}65 \% \leq P \leq \\
79,9 \%\end{array}$ & Baik \\
\hline 3 & $55 \% \leq P \leq$ & Cukup \\
& $64,9 \%$ & \\
\hline 4 & $40 \% \leq P \leq$ & Kurang \\
& $54,9 \%$ & \\
\hline 5 & $0 \% \leq P \leq$ & Sangat \\
& $39,99 \%$ & Kurang \\
\hline
\end{tabular}

Sumber: Arikunto, 2012

8. Berdasarkan hasil perhitungan angket pada gambar 6 di atas, juga diperoleh bahwa persentase para guru sekolah mitra juga orang tua yang memberikan pernyataan sangat setuju terhadap kegiatan pelatihan dan pendampingan sebanyak 54\%; persentase para guru sekolah mitra dan orang tua yang memberikan pernyataan setuju terhadap kegiatan pelatihan dan pendampingan sebanyak 27\%; persentase para guru sekolah mitra dan orang tua yang memberikan pernyataan kurang setuju terhadap kegiatan pelatihan dan pendampingan sebanyak $11 \%$; persentase para guru sekolah mitra dan orang tua yang memberikan pernyataan tidak setuju dan sangat tidak setuju terhadap kegiatan pelatihan dan pendampingan sama-sama memperoleh hasil sebesar 4\%. Berdasarkan hasil persentase angket tersebut, menunjukkan bahwa kegiatan PKM ini telah berhasil meningkatkan pengetahuan, keterampilan, motivasi dan antusiasme para guru dan orang tua terkait kesadaran tentang penggunaan teknologi dalam pembelajaran.

9. Kegiatan diakhiri dengan pemberian motivasi kepada para guru sekolah mitra agar dapat terus meningkatkan pemahaman, pengetahuan, hingga keterampilan dalam menerapkan teknologi yang ada saat ini, karena teknologi akan sangat membantu para guru dalam mengembangkan model pembelajaran agar lebih menarik yang tentunya akan berdampak positif kepada para siswa nantinya. Bahwa di masamasa seperti saat ini proses belajar harus lebih aktif tidak hanya secara offline tetapi bisa juga dilakukan secara online.

\section{KESIMPULAN DAN SARAN}

Dari hasil kegiatan yang dilakukan oleh Tim Hibah PKM Universitas Potensi Utama yang bekerja sama dengan sekolah mitra untuk melaksanakan sebuah metode baru bagi sekolah mitra yaitu mengadakan sistem evaluasi berbentuk ujian yang selama ini menggunakan papar base (berbasis kertas tulis) untuk dapat memanfaatkan teknologi yang ada baik menggunakan aplikasi dan juga media internet. Berdasarkan kegiatan 
yang telah dilaksanakan, maka dapat disimpulkan sebagai berikut:

1. Kegiatan pelatihan yang telah dilakukan mampu memotivasi para guru sekolah mitra dalam meningkatkan pengetahuan dan memahami dalam penggunaan teknologi.

2. Para guru sekolah mitra telah mampu mengembangan sebuah metode evaluasi ujian dan tidak lagi menggunakan sistem paper base tetapi sudah menggunakan aplikasi yang berbasis web yang tentunya menggunakan media internet.

3. Para siswa sebagai bagian yang menggunakan program telah menemukan sebuah metode baru dalam melakukan ujian dengan menggunakan media internet.

4. Berdasarkan hasil persentase angket menunjukkan sebesar 54\% Sangat Setuju, bahwa kegiatan PKM ini dapat meningkatkan pengetahuan, keterampilan, motivasi dan antusiasme para guru dan orang tua terkait kesadaran tentang penggunaan teknologi dalam pembelajaran

\section{UCAPAN TERIMAKASIH}

Program kegiatan ini disponsori dan didanai oleh Kementerian Riset dan Teknologi/Badan Riset dan Inovasi Nasional-Hibah Program Kemitraan Masyarakat (PKM) Tahun 2020 Tahun ke 1 dari rencana 1 tahun sesuai dengan Perjanjian Pelaksanaan Program Pengabdian Masyarakat Nomor: 0433/UPU/PJJ/PPM/VI/2020. Juga kami ucapkan terima kasih kepada pihak Yayasan Nurul Hasanah yang membantu terlaksananya kegiatan ini.

\section{DAFTAR PUSTAKA}

Afgani, M. W., Darmawijoyo, D., \& Purwoko, P. (2008). Pengembangan media website pembelajaran materi program linear untuk siswa sekolah menengah atas. Jurnal pendidikan matematika, 2(2), 45-59.

Aka, K. A. (2017). Pemanfaatan Teknologi Informasi Dan Komunikasi (TIK) Sebagai Wujud Inovasi Sumber Belajar Di Sekolah Dasar. ELSE (Elementary School Education Journal): Jurnal Pendidikan Dan Pembelajaran Sekolah Dasar, 1(2a).

Arikunto, S. (2012). Dasar-dasar evaluasi pendidikan edisi 2. Jakarta: Bumi Aksara.

Ateş, H. (2013). Information technology and the learning environment in primary schools. Procedia-Social and Behavioral Sciences, 93, 695-698.

Heni, H., \& Mujahid, A. J. (2018). Pengaruh Penggunaan Smartphone terhadap Perkembangan Personal Sosial Anak Usia Pra-Sekolah. Jurnal Keperawatan Silampari, 2(1), 330342.

Hussin, N. (2017). Penggunaan laman web sebagai transformasi dalam pengajaran dan pembelajaran pendidikan Islam. O-JIE: Online Journal of Islamic Education, 1(2).

Muhardi, M. (2004). Kontribusi pendidikan dalam meningkatkan kualitas bangsa Indonesia. Mimbar: Jurnal Sosial dan Pembangunan, 20(4), 478-492.

Rachmaniar, R., Prihandini, P., \& Janitra, P. A. (2018). Perilaku penggunaan smartphone dan akses pornografi di kalangan remaja perempuan. Jurnal Komunikasi Global, 7(1), 1-11.

Rolisca, R. U. C., \& Achadiyah, B. N. (2014). Pengembangan Media Evaluasi Pembelajaran Dalam Bentuk Online Berbasis E-Learning Menggunakan Software Wondershare Quiz Creator Dalam Mata Pelajaran Akuntansi SMA Brawijaya Smart School (Bss). Jurnal Pendidikan Akuntansi Indonesia, 12(2).

Sibero, F. K. Alexander, "Web Programming Power Pack," MediaKom, Yogyakarta, 2014.

Sobon, K., Mangundap, J. M., \& Walewangko, S. (2019). Pengaruh 
Penggunaan Smartphone Terhadap Motivasi Belajar Siswa Sekolah Dasar di Kecamatan Mapanget Kota Manado. Autentik: Jurnal Pengembangan Pendidikan Dasar, 3(2), 97-106.

Sudarsana, I. K. (2016). Peningkatan mutu pendidikan luar sekolah dalam upayapembangunan sumber daya manusia. Jurnal Penjaminan Mutu, 1(1), 1-14.

Sudarsana, I. K. (2018). Membentuk Karakter Anak Sebagai Generasi Penerus Bangsa Melalui Pendidikan Anak Usia Dini. Purwadita: Jurnal Agama dan Budaya, 1(1). 